\title{
Research on the Reliability Level of Backhoe Loaders' Diesel Engines
}

\author{
Svetozar Madzhov \\ Forest Research Institute, Bulgarian Academy of Sciences, Sofia 1756, Bulgaria
}

\begin{abstract}
This study identifies the main numerical characteristics of the KOMATSU WB93R-5 backhoe loaders reliability indicators, and sets the resource distribution laws for the engine components of Komatsu SAA4D104E-1. To study the characteristics of the reliability indicators, a methodology for experimental research has been developed, using the complex, comparative and formal method, as well as the systematic, cybernetic and statistical approach.
\end{abstract}

Key words: Reliability, maintenance, R (Repair), engine, backhoe loader.

\section{Introduction}

At the current stage of economic development, the problem of increasing the efficiency of using machines, which are the active part of the basic production funds and determine the production capabilities of the business organization, is especially relevant.

As the technical level of the machines increases, their complexity and productivity increase, the equipment becomes more expensive. For TM (Technical Maintenance) and R (Repair) during the machines lifetime, twice as much money is spent as on their purchase, this ratio being different for different types of machines [1-3]. The main trend, however, is clear-the relative share of the service complex in the overall balance of production means is constantly growing.

A significant cost reduction in the service complex can be achieved by optimizing the structure and parameters of the system for TM and R of equipment with different methods and models. This requires that the numerical characteristics of the reliability indices of the machine components be studied in order to develop an efficient system of maintenance and $\mathrm{R}$, guaranteeing the efficient use of the machines.

Corresponding author: Svetozar Madzhov, Ph.D., assistant professor, main research field: forest mechanization and reliability.

\section{Materials and Methods}

The purpose of the study is to determine the basic numerical characteristics of reliability indicators of the KOMATSU WB93R-5 backhoe loaders.

To study the characteristics of the reliability indicators, we develop a methodology for experimental research using the complex, comparative and formal method, as well as the systematic, cybernetic and statistical approach.

The complex method was used to evaluate the technical condition of the backhoe loader, the level of reliability of its elements, the internal interconnection of the factors affecting the intensity of the processes which deteriorate the technical condition of the machine. The components technical condition assessment has been carried out by complex indicators.

The essence of the formal method lies in the construction of models with effective mathematical methods. Models are best suited for analysing complex systems and making effective management decisions.

The comparative method was used at almost all stages of the study to compare the information obtained and to take into account the influence of various objective and subjective factors on the level of reliability of the study objects.

The process of occurrence of failures and changes in the state of the study object's elements is random 
(stochastic), and specific and complex indicators based on statistical information are used to assess the level of elements reliability. Obtaining the statistical characteristics of the indicators is based on the methods of probability theory and mathematical statistics. The systematic approach is applied to select the best solution in the presence of several possible options. Such cases are typical of determining the number of spare parts for the equipment, where there are many acceptable solutions of which the optimal one could be chosen, especially when it comes to allocating a stock of spare parts. The cybernetic approach enables the object under study to be regarded as a system with definite structure, properties, input and output parameters. At the same time, each object is viewed not as an indivisible whole, but as a system of interconnected elements with their properties and quality characteristics. As a result of the system analysis, the best solutions are selected for both the system as a whole and the elements individually.

These methods and approaches will be used in the study of different processes, parameters and models and for drawing up conclusions.

The study was performed under the machines' operational conditions: a set of natural, climatic, production, technical, economic, organizational and social factors affecting the intensity of the change of their state parameters. The survey was carried out for the territory of the Republic of Bulgaria in the head office of Kirov AD in Sofia and Sofia region. Study subjects were: 180 backhoe loaders operating year-round, and the nominal operation fund was 2,128 hours per year; 177 hours per month. The survey was conducted for a period of 4 years during 2010-2014. We also have partial information for 2014, but we will not analyse it at this stage.

In each test, the following four phases can be defined: test planning, test conducting, processing of test results, result analysis and decision selection [4-8].
In this particular study, authors will focus mainly on the analysis of the research results and suggestions for theory and practice.

The basic information on the malfunctions of the SAA4D104E-1 engine of KOMATSU WB93R-5 backhoe loaders is classified according to the following basic principles: origin, cause of occurrence, remedy complexity, type of elements, consequences of failures, nature of manifestation and way of elimination.

The source information was collected at construction companies in southern Bulgaria and includes 39 backhoes. The data collected are from direct observations and information maps from March 2009 until July 2010, and data from business organizations' reports for the preceding six years. The data were collected according to the developed methodology of the experimental study, classified by elements and grouped according to the below-listed classification features, properties and reliability indicators.

\section{Results and Discussion}

The distribution of failures by reason of the failure (quality of workmanship; design defects; broken rules of operation; continuous operation; normal wear and tear; quality of R) is shown in Fig. 1.

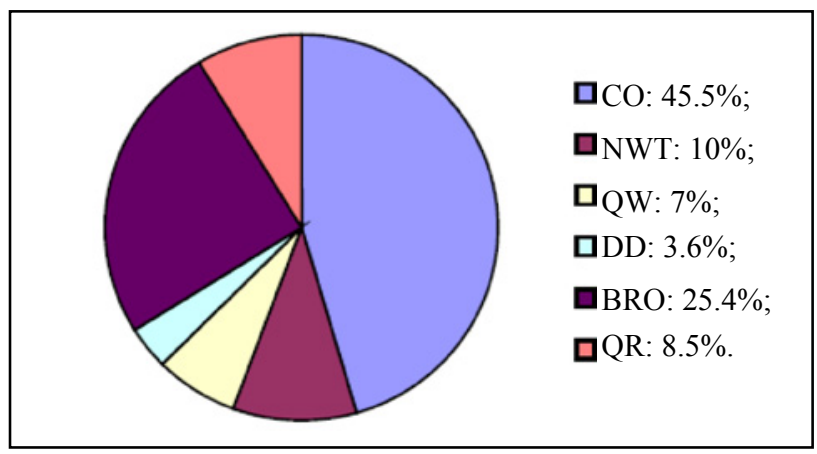

Fig. 1 Distribution of failures by reason of occurrence. $\mathrm{CO}$ - continuous operation;

NWT — normal wear and tear;

QW-quality of workmanship;

DD—design defects;

$\mathrm{BRO}$ - broken rules of operation;

QR — quality of Repair. 
Analysing the types of failures due to their occurrence, authors found that the largest number of failures was due to breakage of parts and units- $56 \%$, and $44 \%$ - due to violation of the regulatory parameters.

From the analysis of the information on the reliability of KOMATSU WB93R-5 backhoe loaders elements, authors found that the highest percentage was held by failures of fuel system elements, so Tables 1 and 2 present the distribution of failures of fuel system elements. The distribution of failures by external manifestation is shown in Table 1.

It has been found that the proportion of malfunctions of the fuel system elements on the level of reliability is different, and this is substantial after overhauls.

\subsection{Research on the Reliability of the Backhoes'} Combustion System Elements

The trouble-free operation of the backhoe's combustion system was evaluated by the operation between failures, failure flow and characteristics: average number of failures $\overline{\boldsymbol{m}}(t)$; fault flow parameter $w(t)$ and operation between faults $\bar{t}_{.,}$.

The values of the numerical characteristics of failure are given in Table 3. The data analysis shows that the level of combustion system components reliability up to overhaul is about 2 times higher than that between Rs.

The operation between failures $t_{\mathrm{m}}$ is distributed according to the Weibull law with parameters $a=$ 669.7 motor hours; $b=2.0 ; c=252$ motor hours. The Weibull law hypothesis is not rejected for significant level $\alpha=0.10$ and degrees of freedom $k=2$.

The main numerical characteristics of operation between failures are $\bar{t}_{. \mu}=858.7$ motor hours; $\sigma=$ $284.35 ; \vartheta=0.33$.

The numerical characteristics and parameters of the distribution laws of operation up to the combustion system elements failure are given in Tables 4 and 5 .

Table 1 External manifestation of failures.

\begin{tabular}{lll}
\hline No. & External manifestation & \% of failures \\
\hline A & Broken parts and assemblies & \\
1. & Camshaft bearing & 27.2 \\
2. & Damage to the tightness of the seal & 11.8 \\
3. & Fuel feed pump & 4.9 \\
4. & Check valve spring & 4.1 \\
5. & Spring of the pusher & 3.7 \\
6. & Regulator connector & 4.2 \\
B. & Infringed control parameters & 16.1 \\
7. & Increasing feed unevenness & 13.9 \\
8. & Reducing the minimum cycle feed & 7.8 \\
9. & Decrease of rotation speed and start of controller switching on & 6.2 \\
10. & Decrease in enrichment rate & \\
\hline
\end{tabular}

Table 2 Breakdown of combustion system failures by units and units.

\begin{tabular}{lll}
\hline \multirow{2}{*}{ Components and units } & \multicolumn{2}{c}{ Number of failures per backhoe } \\
\cline { 2 - 3 } & Up to overhaul & Between overhauls \\
\hline Fuel pumps & 0.30 & 0.55 \\
Nozzles & 0.68 & 0.65 \\
High pressure fuel line & 0.52 & 0.43 \\
Low pressure fuel line & 0.74 & 1.62 \\
Filters for coarse fuel cleaning & - & 0.06 \\
Filters for fine fuel cleaning & 0.27 & 0.19 \\
Overall the engine & 2.51 & 3.50 \\
\hline
\end{tabular}


Table 3 Characteristics of the combustion system reliability.

\begin{tabular}{llll}
\hline Characteristic of reliability & \multirow{2}{*}{ Designation } & \multicolumn{2}{c}{ Numerical characteristics } \\
\cline { 3 - 4 } Average number of failures per 3,000 motor hours, number & $\bar{m}$ & 3.60 & Between overhauls \\
Failure flow parameter, 1/motor hours $\times 10^{-5}$ & $w(t)$ & 127 & 7.20 \\
Operation between failures, motor hours & $\bar{t}_{\text {.н }}$ & 856.3 & 234 \\
\hline
\end{tabular}

Table 4 Main numerical characteristics of the operation until combustion system elements failure.

\begin{tabular}{lllll}
\hline \multirow{2}{*}{ No. } & Name & \multicolumn{3}{c}{ Basic numerical characteristics, motor $\mathrm{h}$} \\
\cline { 3 - 4 } & & $t \times 10^{3}$ & $\sigma \times 10^{3}$ & $\vartheta$ \\
\hline 1 & High pressure fuel line & 142.0 & 31.7 & 0.50 \\
2 & Pipeline outlet to nozzle, assembly & 45.4 & 12.0 & 0.40 \\
3 & Overflow pipeline, assembly & 58,0 & 13.8 & 0.20 \\
4 & Tube to filter, assembly & 48,0 & 6.5 & 0.32 \\
5 & Tube to pump, assembly & 28.7 & 6.7 & 0.45 \\
6 & Fuel filter for rough cleaning & 46.4 & 13.9 & 0.55 \\
7 & Fuel filter, assembly & 38.0 & 10.8 & 0.25 \\
8 & Fuel filter spring & 27.9 & 3.6 & 0.26 \\
9 & Crankshaft Bolt & 29.9 & 4.3 & 0.31 \\
10 & Ring sealing & 9.5 & 2.70 & 0.35 \\
11 & Filter with bracket & 89.0 & 22.7 & 0.35 \\
12 & Reflector & 0.76 & 0.24 & 0.65 \\
13 & Filter element & 0.90 & 0.40 & 0.60 \\
14 & Wing profile, set & 18.5 & 9.0 & 0.20 \\
15 & Purge hole needle & 9.5 & 1.35 & \\
\hline
\end{tabular}

Table 5 Parameters of the laws of operation distribution up to combustion system elements failure.

\begin{tabular}{lllll}
\hline \multirow{2}{*}{ No. } & Name & \multicolumn{3}{c}{ Parameter, motor h } \\
\cline { 3 - 4 } & & $a$ & $b$ & 80.0 \\
2 & High pressure fuel line & 70.44 & 2.05 & 15.2 \\
3 & Pipeline outlet to nozzle, assembly & 31.58 & 2.60 & 20.5 \\
4 & Overflow pipeline, assembly & 40.58 & 2.40 & 12.2 \\
5 & Tube to filter, assembly & 25.35 & 4.20 & 5.8 \\
6 & Tube to pump, assembly & 22.68 & 3.50 & 12.6 \\
7 & Fuel filter for rough cleaning & 34.75 & 2.35 & 16.5 \\
8 & Fuel filter spring & 22.04 & 1.90 & 9.5 \\
9 & Crankshaft bolt & 15.72 & 4.15 & 1.5 \\
10 & Ring sealing & 17.67 & 3.75 & 20.6 \\
11 & Filter with bracket & 9.64 & 3.60 & 0.08 \\
12 & Reflector & 73.26 & 3.10 & 0.28 \\
13 & Filter element & 0.77 & 3.10 & 0.70 \\
14 & Wing profile, set & 0.70 & 1.55 & 1.10 \\
15 & Purge hole needle & 16.67 & 1.70 & \\
\hline
\end{tabular}


Table 6 Basic numerical characteristics, parameters, and resource distribution laws of Komatsu SAA4D104E-1 elements of Komatsu WB93R-5 backhoe loaders.

\begin{tabular}{|c|c|c|c|c|c|c|}
\hline \multirow{2}{*}{ No. } & \multirow{2}{*}{ Exchange elements } & \multicolumn{4}{|c|}{ Ratings of the main numerical characteristics and parameters } & \multirow{2}{*}{-Distribution laws } \\
\hline & & top $(a)$ & $\sigma(b)$ & $V$ & $c$ & \\
\hline 1 & Engine & $\begin{array}{l}20,705 \\
(23,329)\end{array}$ & $\begin{array}{l}11,925 \\
(2,64)\end{array}$ & 0.472 & - & $\mathrm{B}$ \\
\hline 2 & Cylinder head & 22,392 & 7,333 & 0.533 & 8,537 & - \\
\hline 3 & Nozzle & $\begin{array}{l}14,254 \\
(15,932)\end{array}$ & $\begin{array}{l}6,834 \\
(2,54)\end{array}$ & 0.486 & - & $\mathrm{B}$ \\
\hline 4 & Fuel pump & 24,786 & 12,751 & 0.540 & 601 & $\mathrm{~B}$ \\
\hline 5 & Pump supp. & 24,920 & 9,440 & 0.413 & 1,043 & - \\
\hline 6 & Oil pump & 42,354 & 14,839 & 0.356 & 12,934 & IM \\
\hline 7 & Water pump & $\begin{array}{l}21,486 \\
(23,841)\end{array}$ & $\begin{array}{l}12,073 \\
(1,803)\end{array}$ & 0.573 & - & $\mathrm{B}$ \\
\hline 8 & Radiator & 27,833 & 8,502 & 0.648 & 13,617 & - \\
\hline
\end{tabular}

Table 7 Gamma percentage resource of Komatsu SAA4D104E-1 elements in KOMATSU WB93R-5 backhoe loader.

\begin{tabular}{lll}
\hline No. & Element & $80 \%$ gamma resource, litres \\
\hline 1 & Engine & 13,271 \\
2 & Cylinder head & 18,920 \\
3 & Nozzle & 7,842 \\
4 & Fuel pump & 19,935 \\
5 & Pump supp. & 17,837 \\
6 & Oil pump & 29,760 \\
7 & Water pump & 10,702 \\
8 & Radiator & - \\
\hline
\end{tabular}

Table 8 Characteristics of the combustion system durability.

\begin{tabular}{llll}
\hline Characteristics of durability & Definition & \multicolumn{2}{c}{ Numerical characteristics values } \\
\cline { 3 - 4 } Resource, motor hours & $\bar{T}$ & 5,420 & between overhauls \\
Gamma percentage resource, motor hours & $T_{\gamma=0.80}$ & 4,877 & 998 \\
Service life, years & $T_{e}$ & 7.60 & 3.49 \\
Range of percent lifetime, years & $T_{e \gamma=0.80}$ & 8.38 & 2.97 \\
\hline
\end{tabular}

\subsection{Durability Testing of Komatsu SAA4D104E-1} Diesel Engine Components on the KOMATSU WB93R-5 Backhoe Loader

The basic numerical characteristics, parameters of the distribution of the life of the aggregates and units (exchange elements) of the Komatsu SAA4D104E-1 engine in the KOMATSU WB93R-5 backhoe loaders have been determined on the basis of the experimental testing methodology, presented in Table 6, and the gamma percentage resource for $\gamma=80 \%$ in Table 7 .

The analysis of the data in Table 8 shows that the $80 \%$ engine life to major Rs is less than the normative value of about 1.5 times and between the major
Rs-9.5-10 times.

The main characteristics of the combustion system components durability are presented in Table 8.

\subsection{Examination of the Major R Performance Indicators of Komatsu SAA4D104E-1 Engine Components of the KOMATSU WB93R-5 Backhoe Loaders}

The study and determination of the time for replacement of tractor elements under the condition of partial mechanization of $\mathrm{R}$ and maintenance work were performed according to the methods given in the experimental testing methodology, and the basic numerical characteristics and conditions for the 
Table 9 Timing for the replacement of Komatsu SAA4D104E-1 engine elements on KOMATSU WB93R-5 Backhoe Loaders.

\begin{tabular}{|c|c|c|c|c|c|c|c|c|}
\hline \multirow{2}{*}{ No. } & \multirow{2}{*}{ Exchange elements } & \multirow{2}{*}{$\begin{array}{l}\text { Medium } \\
\text { rate }\end{array}$} & \multirow{2}{*}{$\begin{array}{l}\text { Number of } \\
\text { workers }\end{array}$} & \multirow{2}{*}{\multicolumn{2}{|c|}{$\begin{array}{l}\text { Replacement time by } \\
\text { standard, h (man hours) }\end{array}$}} & \multicolumn{3}{|c|}{ Expert evaluation replacement time, $\mathrm{h}$} \\
\hline & & & & & & $\overline{t_{\mathrm{cp}}}$ & $\sigma$ & $V_{x}$ \\
\hline 1 & Engine & 3.5 & 2 & 3.80 & $(7.50)$ & 11.2 & 3.1 & 0.276 \\
\hline 2 & Cylinder head & 3.3 & 2 & 3.78 & $(7.55)$ & 4.4 & 1.1 & 0.25 \\
\hline 3 & Nozzle & 3.6 & 2 & 0.38 & $(0.76)$ & 0.4 & 0.1 & 0.25 \\
\hline 4 & Fuel pump & 3.5 & 2 & 3.80 & $(7.50)$ & 1.8 & 0.6 & 0.33 \\
\hline 5 & Pump supp. & 2.5 & 1 & 0.27 & $(0.27)$ & 0.4 & 0.1 & 0.25 \\
\hline 6 & Oil pump & 2.5 & 1 & 0.18 & $(0,18)$ & 2.2 & 0.7 & 0.32 \\
\hline 7 & Water pump & 2.7 & 2 & 2,31 & $(4.62)$ & 2.5 & 0.6 & 0.24 \\
\hline 8 & Radiator & 3.4 & 2 & 1.93 & (3.86) & 3.2 & 0.9 & 0.28 \\
\hline
\end{tabular}

Table 10 Time consumption for engine maintenance.

\begin{tabular}{llllll}
\hline $\begin{array}{l}\text { TO } \\
\text { No. }\end{array}$ & $\begin{array}{l}\text { Frequency, motor } \\
\text { hours }\end{array}$ & $\begin{array}{l}\text { Number of TO for } \\
960 \text { motor hours }\end{array}$ & Operations by TO & $\begin{array}{l}\text { Time limit for 1 } \\
\text { servicing } \\
\text { operation }\end{array}$ & $\begin{array}{l}\text { Total time } \\
\text { consumption for 960 } \\
\text { motor hours, hour }\end{array}$ \\
\hline 1 & 60 & 12 & $\begin{array}{l}\text { Check oil level in the pump housing, } \\
\text { top up when needed }\end{array}$ & 1.75 & 0.37 \\
2 & 240 & 3 & $\begin{array}{l}\text { Change the oil in the pump housing } \\
\text { Check and adjust if necessary on a stand } 8.6\end{array}$ & 0.32 \\
4 & 960 & 0.5 & Oil change & 7.8 & 0.75 \\
\hline
\end{tabular}

replacement of KOMATSU WB93R-5 backhoe loaders elements are presented in Table 9.

The $\mathrm{R}$ suitability of the engines is most fully assessed by the annual cost of its serviceability maintenance. For the evaluation of this reliability indicator, the average relative labour intensity feature for technical servicing $T_{T O}$ and troubleshoot $T_{O H}$ is often used related to 1,000 hours of operation:

$$
T_{\text {TO }}=\frac{T_{T}}{T} 1000 ; \quad T_{\text {OH }}=\frac{T_{H}}{T} 1000,
$$

where $T$ is the established maintenance workload;

$T_{T}$ and $T_{H}$ are the time consumed for TM TO and for troubleshooting for a given resource.

The $T_{T O}$ and $T_{O H}$ characteristics can be calculated for the engine as a whole or by elements. Table 10 gives the numerical characteristics of the engine maintenance time.

As Table 10 demonstrates, for the pump maintenance for 960 hours of engine operation, 1,505 hours have been spent. Accordingly, the relative labour load of engine maintenance will be:

$$
T_{\text {TO }}=\frac{1,505}{960} 1000=1,568 \text { hours }
$$

Similarly, the relative labour load for maintenance was calculated also for the $\mathrm{R}$ of other engine components in Table 11.

\subsection{Examination of the Exchange Elements Request Parameter for the KOMATSU WB93R-5 Komatsu SAA4D104E-1 Engine for KOMATSU WB93R-5 Backhoe Loaders}

The basic numerical characteristics and exchange elements request flow distribution law of Komatsu SAA4D104E-1 engine for KOMATSU WB93R-5 Backhoe loaders are presented in Table 12.

\section{Main Conclusions}

The largest number of failures was found to be due to breakage of parts and assemblies- $56 \%$ and $44 \%$ - due to breach of the regulatory parameters.

The laws of resource allocation of Komatsu SAA4D104E-1 engine components have been established. According to Pearson's criterion, 50\% of the components of the Komatsu SAA4D104E-1 L engine were found to be distributed according to the Weibull distribution law. 
Table 11 Consumption of maintenance time and relative labour load of engine components maintenance.

\begin{tabular}{llllll}
\hline \multirow{2}{*}{ No. } & Exchange elements & \multicolumn{3}{c}{ Estimates of basic numerical characteristics, $\mathrm{h}}$. & Distribution laws \\
\cline { 3 - 5 } & & $X_{c p}$ & $\sigma$ & $V_{x}(\%)$ & $\mathrm{P}$ \\
2 & Engine & 3.85 & 1.90 & 49.35 & $\mathrm{P}$ \\
3 & Cylinder head & 1.30 & 1.35 & 103.85 & $\mathrm{P}$ \\
4 & Nozzle & 12.00 & 3.60 & 30.00 & $\mathrm{P}$ \\
5 & Fuel pump & 1.46 & 1.18 & 84.29 & $\mathrm{P}$ \\
6 & Oil pump & 1.50 & 1.10 & 73.33 & $\mathrm{P}$ \\
7 & Water pump & 4.80 & 1.90 & 39.58 & $\mathrm{P}$ \\
8 & Radiator & 2.00 & 0.97 & 75.00 & $\mathrm{P}$ \\
\hline
\end{tabular}

Table 12 Basic numerical characteristics and exchange elements request flow distribution law of Komatsu SAA4D104E-1 engine for KOMATSU WB93R-5 Backhoe loaders.

\begin{tabular}{llll}
\hline No. & Elements of the system & Total time consumption for 960 motor hours, $\mathrm{h}$ & $T_{T O}$, man $\mathrm{h}$ \\
\hline 1 & Fuel pump & 1.05 & 1.568 \\
2 & Nozzles & 5.985 & 6.225 \\
3 & Filters, etc. & 2.05 & 2.204 \\
\hline
\end{tabular}

The $80 \%$ gamma-resource of Komatsu SAA4D104E-1 engine elements with known and unknown distribution law and concise (censored) samples has been determined.

Increasing the level of reliability of engine components must be achieved by improving the quality of $\mathrm{R}$ and increasing the number of spare parts.

\section{References}

[1] Kozlovskiy, V. A., et al. 1998. Logistics. Sofia, Bulgaria.

[2] Mirotin, L. B., et al. 2000. Fundamentals of Logistics.
Moscow, Russia.

[3] Chervonyi, A., Lukyashtenko, V., and Kotin, L. 1972. Reliability of Complex Systems. Moscow, Russia.

[4] Lukinskiy, A. M. 2000. Road Transport Logistics. Moscow, Russia.

[5] Mihov, M., and Tasev, G. 2012. Machinery Maintenance and Repair. Sofia, Bulgaria, p. 149.

[6] Spiridonov, G., and Tasev, G. 1981. Some Theoretical and Applied Aspects of the Repair and Maintenance of Agricultural Machinery. Rousse, Bulgaria.

[7] Skovorodin, V., Tishkin, L., and Tasev, G. 1990. AM Reliability Reference Book. Sofia, Bulgaria, p. 245.

[8] Howard, K., et al. 1998. Marketing. Moscow, Russia. 